\title{
Predictors of Nonseroconversion after SARS-CoV-2 Infection
}

\author{
Weimin Liu, ${ }^{1}$ Ronnie M. Russell, ${ }^{1}$ Frederic Bibollet-Ruche, ${ }^{1}$ Ashwin N. Skelly, ${ }^{1}$ \\ Scott Sherrill-Mix, ${ }^{1}$ Drew A. Freeman, ${ }^{1}$ Regina Stoltz, Emily Lindemuth, Fang-Hua Lee, \\ Sarah Sterrett, Katharine J. Bar, Nathaniel Erdmann, Sigrid Gouma, Scott E. Hensley, Thomas Ketas, \\ Albert Cupo, Victor M. Cruz Portillo, John P. Moore, Paul D. Bieniasz, Theodora Hatziioannou, \\ Greer Massey, Mary-Beth Minyard, ${ }^{2}$ Michael S. Saag, Randall S. Davis, George M. Shaw, \\ William J. Britt, Sixto M. Leal, Jr., Paul Goepfert, Beatrice H. Hahn
}

Not all persons recovering from severe acute respiratory syndrome coronavirus 2 (SARS-CoV-2) infection develop SARS-CoV-2-specific antibodies. We show that nonseroconversion is associated with younger age and higher reverse transcription PCR cycle threshold values and identify SARS-CoV-2 viral loads in the nasopharynx as a major correlate of the systemic antibody response.

Coronavirus disease (COVID-19) is typically diagnosed by reverse transcription PCR (RT-PCR) amplification of severe acute respiratory syndrome coronavirus 2 (SARS-CoV-2) RNA from nasopharyngeal fluids (1). RT-PCR yields cycle threshold $\left(\mathrm{C}_{t}\right)$ values that are inversely correlated with viral loads (2) and thus provide an estimate of the number of SARS-CoV-2 RNA copies in the sample. Serologic assays complement COVID-19 diagnosis by documenting past infections. In most persons, binding and neutralizing antibodies develop within 1-3 weeks after onset of symptoms (3), and titers correlate with disease severity (4).

Initial serosurveys identified antibodies in nearly $100 \%$ of persons with RT-PCR-confirmed SARSCoV-2 infection (5). However, more recent studies

Author affiliations: University of Pennsylvania, Philadelphia, Pennsylvania, USA (W. Liu, R.M. Russell, F. Bibollet-Ruche, A.N. Skelly, S. Sherrill-Mix, R. Stoltz, E. Lindemuth, F.-H. Lee, K.J. Bar, S. Gouma, S.E. Hensley, G.M. Shaw, B.H. Hahn); The University of Alabama at Birmingham, Birmingham, Alabama, USA (D.A. Freeman, S. Sterrett, N. Erdmann, M.S. Saag, R.S. Davis, W.J. Britt, S.M. Leal Jr., P. Goepfert); Weill Cornell Medicine, New York, New York, USA (T. Ketas, A. Cupo, V.M. Cruz Portillo, J.P. Moore); Howard Hughes Medical Institute, New York (P.D. Bieniasz); The Rockefeller University, New York (P.D. Bieniasz, T. Hatziioannou); Assurance Scientific, Vestavia, Alabama, USA (G. Massey, M.-B. Minyard)

DOI: https://doi.org/10.3201/eid2709.211042 have shown that seroconversion rates are surprisingly variable (6-10). For example, a multicenter study from Israel reported that $5 \%$ of participants remained seronegative despite a positive test result on a nasal swab specimen (6). In contrast, a seroprevalence study from New York found that $20 \%$ of persons with a positive RT-PCR test result did not seroconvert (8). Another study from Germany reported that $85 \%$ of confirmed infected COVID-19 contacts failed to develop antibodies (9). To examine the reasons for these differences, we investigated the relationship between seroconversion and demographic, clinical, and laboratory data in a convenience sample of convalescent persons recruited at the University of Alabama at Birmingham (Birmingham, Alabama, USA) in 2020.

\section{The Study}

We studied 72 persons, all of whom had a previous positive RT-PCR test but were symptom-free for $>3$ weeks before blood was collected for testing (Table). Only 2 persons $(3 \%)$ reported no symptoms, whereas $13(18 \%)$ persons reported mild disease, $48(67 \%)$ reported moderate disease, and $9(12 \%)$ reported severe disease (Appendix Table 1, https:/ / wwwnc.cdc.gov/ EID/article/27/9/21-1024-App1.pdf).

We tested plasma samples $(n=144)$ collected at enrollment and follow-up visits for antibodies to the spike protein by using a validated ELISA (Appendix). Only 46 of the 72 participants had detectable IgG responses, IgA responses, or both (Table); reciprocal endpoint titers ranged from 182 to $>312,500$ (Appendix Table 2). Analysis of the same samples for receptor-binding domain (RBD) and nucleocapsid (N)

\footnotetext{
'These first authors contributed equally to this article.

${ }^{2}$ Current affiliation: MBMicrobio Labs, Birmingham, Alabama, USA.
} 
Table. Demographic, clinical, and laboratory characteristics of serologic responders and nonresponders after SARS-CoV-2 infection*

\begin{tabular}{|c|c|c|c|}
\hline Characteristic & $\begin{array}{l}\text { SARS-CoV-2 antibody } \\
\text { positive, } n=46\end{array}$ & $\begin{array}{l}\text { SARS-CoV-2 antibody } \\
\text { negative, } n=26\end{array}$ & $p$ value $†$ \\
\hline Age, y, median (IQR) & $49(37-63)$ & $35(30-46)$ & 0.03 \\
\hline Sex & & & 0.17 \\
\hline $\mathrm{M}$ & $30(65)$ & $10(38)$ & \\
\hline $\mathrm{F}$ & $16(35)$ & $16(62)$ & \\
\hline Race/ethnicity & & & 1.00 \\
\hline White & $28(61)$ & $20(77)$ & \\
\hline Black & $7(15)$ & $3(12)$ & \\
\hline Asian & $7(15)$ & $3(12)$ & \\
\hline Latinx & $4(9)$ & 0 & \\
\hline \multicolumn{4}{|l|}{ RT-PCR of nasal swabs } \\
\hline DFOS, d, median (IQR) & $5(3-11)$ & $5(4-8)$ & 0.95 \\
\hline$C_{t}$ value, median (IQR) & $24.5(22-27)$ & $36(34-77)$ & $<0.00001$ \\
\hline Symptoms§ & $45(98)$ & $25(96)$ & 0.21 \\
\hline Severity 0 & $1(2)$ & $1(4)$ & \\
\hline Severity 1 & $5(11)$ & $8(31)$ & \\
\hline Severity 2 & $33(72)$ & $15(58)$ & \\
\hline Severity 3 & $7(15)$ & $2(8)$ & \\
\hline Hospitalization & $6(13)$ & $2(8)$ & 1.00 \\
\hline \multicolumn{4}{|l|}{ Serologic analyses } \\
\hline DFOS of T1, d, median (IQR) & $34(26-46)$ & $33(22-43)$ & 0.74 \\
\hline \multicolumn{4}{|l|}{ Binding antibodies positivef } \\
\hline Spike protein IgG\# & $46(100)$ & 0 & \\
\hline Spike protein IgA\# & $43(93)$ & 0 & \\
\hline$R B D \lg G^{* *}$ & $44(96)$ & 0 & \\
\hline RBD $\lg ^{\star *}$ & $38(83)$ & 0 & \\
\hline Nucleocapsid protein IgG†† & $43(93)$ & 0 & \\
\hline Neutralizing antibodies positiveI & $45(98)$ & 0 & \\
\hline \multicolumn{4}{|c|}{ 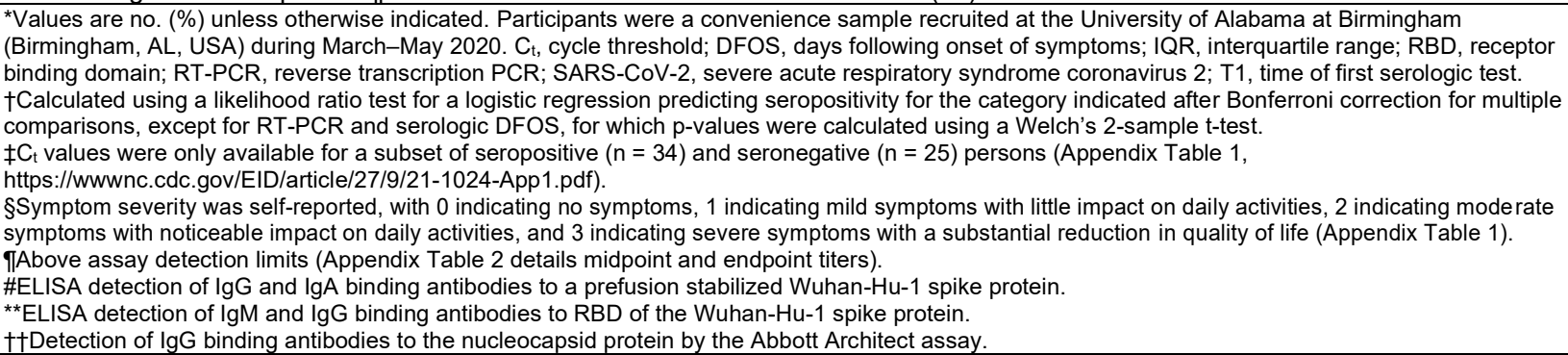 } \\
\hline
\end{tabular}

antibodies yielded very similar results (Appendix Figure 1). All persons with spike protein antibodies also had detectable RBD (IgG, IgM, or both) or N (IgG) protein responses, except for 1 participant whose spike protein endpoint titers were very low (Appendix Table 2). In contrast, 26 participants remained seronegative, despite the testing of up to 3 samples per person for IgA, IgM, and IgG against multiple antigens as well as neutralizing antibodies. Thus, $36 \%$ of our cohort represented serologic nonresponders.

To investigate potential reasons for the lack of seroconversion, we examined available demographic, clinical, and laboratory data. Comparing race/ethnicity, sex, and symptom severity, we failed to find a significant association with serostatus (Table), although we did observe a trend for increasing antibody positivity with increasing symptom severity (Appendix Figure 2). We also found no significant differences in seroconversion between patients reporting or not reporting various symptoms, including symptoms characteristic of COVID-19 (Appendix Figure 3). However, seronegative persons were on average 10 (95\% CI 3-17) years younger than seropositive persons (Figure 1, panel A) and exhibited RT-PCR C values that were 11 (95\% CI 8-14) cycles higher (Figure 1 , panel B). Moreover, logistic regression showed a precipitous decline in the probability of seroconversion at higher $C_{t}$ values (Figure 2). For example, a $C_{t}$ of 35 predicted only a $15 \%$ (95\% CI $5 \%-37 \%)$ probability of seroconversion, which decreased further with increasing $C_{t}$ values. Thus, low nasopharyngeal viral loads seem insufficient to elicit a systemic antibody response.

For control, we plotted $C_{t}$ values of serologic responders and nonresponders against the times of RTPCR and antibody testing relative to symptom onset (Appendix Figure 4). In both cases, the distributions of sampling times were similar for the 2 groups, thus excluding the possibility that seronegative persons had higher $C_{t}$ values because they were tested too late 

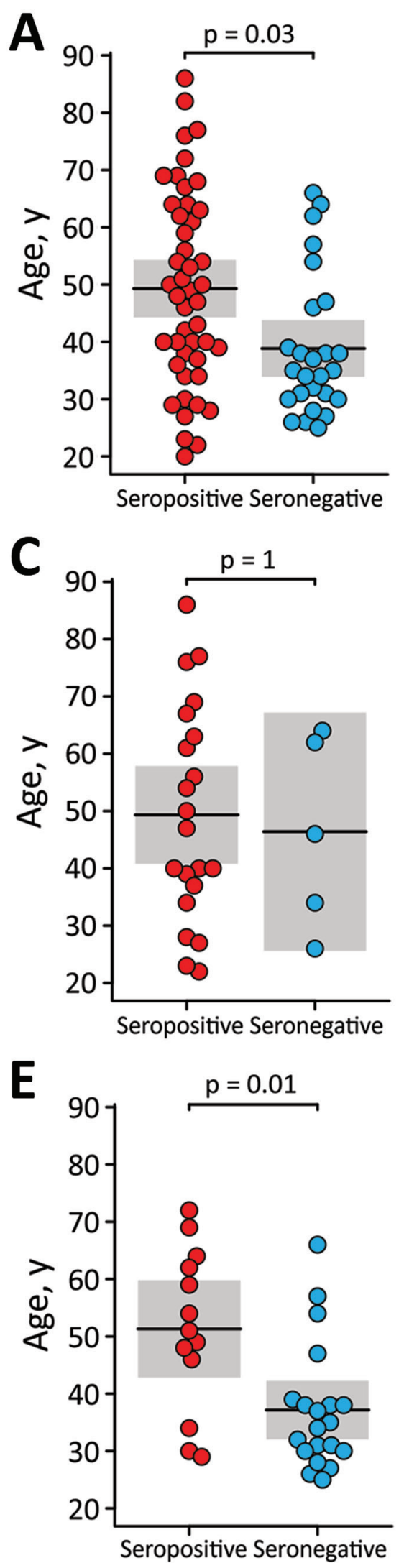
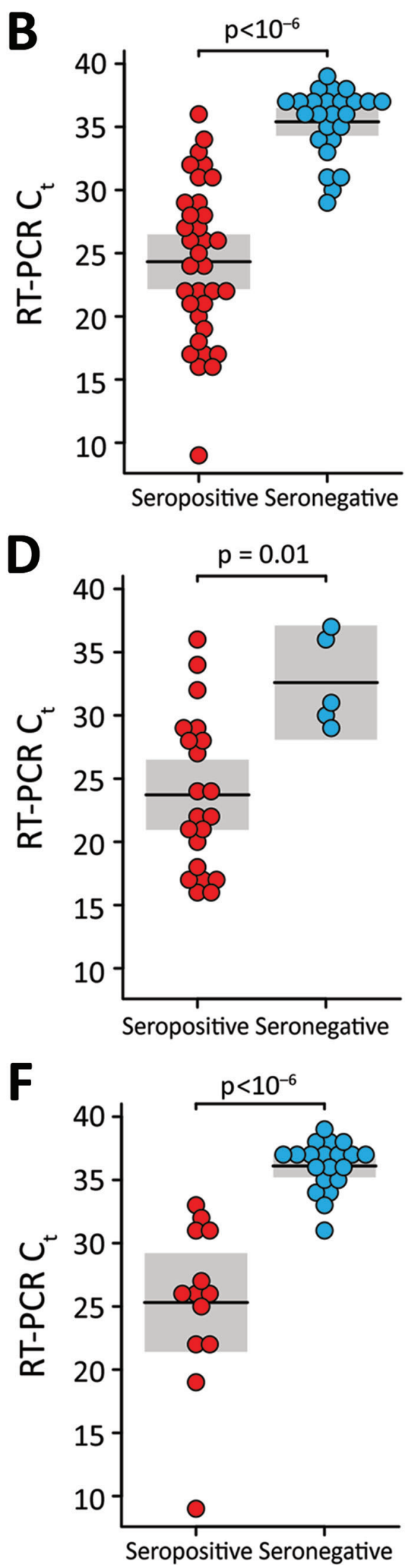

Figure 1. Relationship of age and nasopharyngeal viral loads with SARS-CoV-2 serostatus among convalescent persons after SARSCoV-2 infection. Participants were a convenience sample of convalescent SARS-CoV-2-infected persons recruited at the University of Alabama at Birmingham,

Birmingham, Alabama, USA, 2020. Age (panels A, C, and E) and RTPCR $C_{t}$ values (panels $B, D$, and $F$ ) are plotted for seropositive (red) and seronegative (blue) persons. Panels show comparisons of persons tested at all sites (panels A, B), the Assurance Scientific Laboratories site (panels B, C), and the University of Alabama at Birmingham

Fungal Reference Laboratory and Children's of Alabama Diagnostic Virology Laboratory sites (panels E, F). The mean (horizontal line) and corresponding $95 \% \mathrm{Cl}$ (shading) are shown; $p$-values indicate the results of a likelihood ratio test after Bonferroni correction for multiple comparisons. $\mathrm{C}_{\mathrm{t}}$, cycle threshold; RT-PCR, reverse transcription PCR; SARS-CoV-2, severe acute respiratory syndrome coronavirus 2 . 


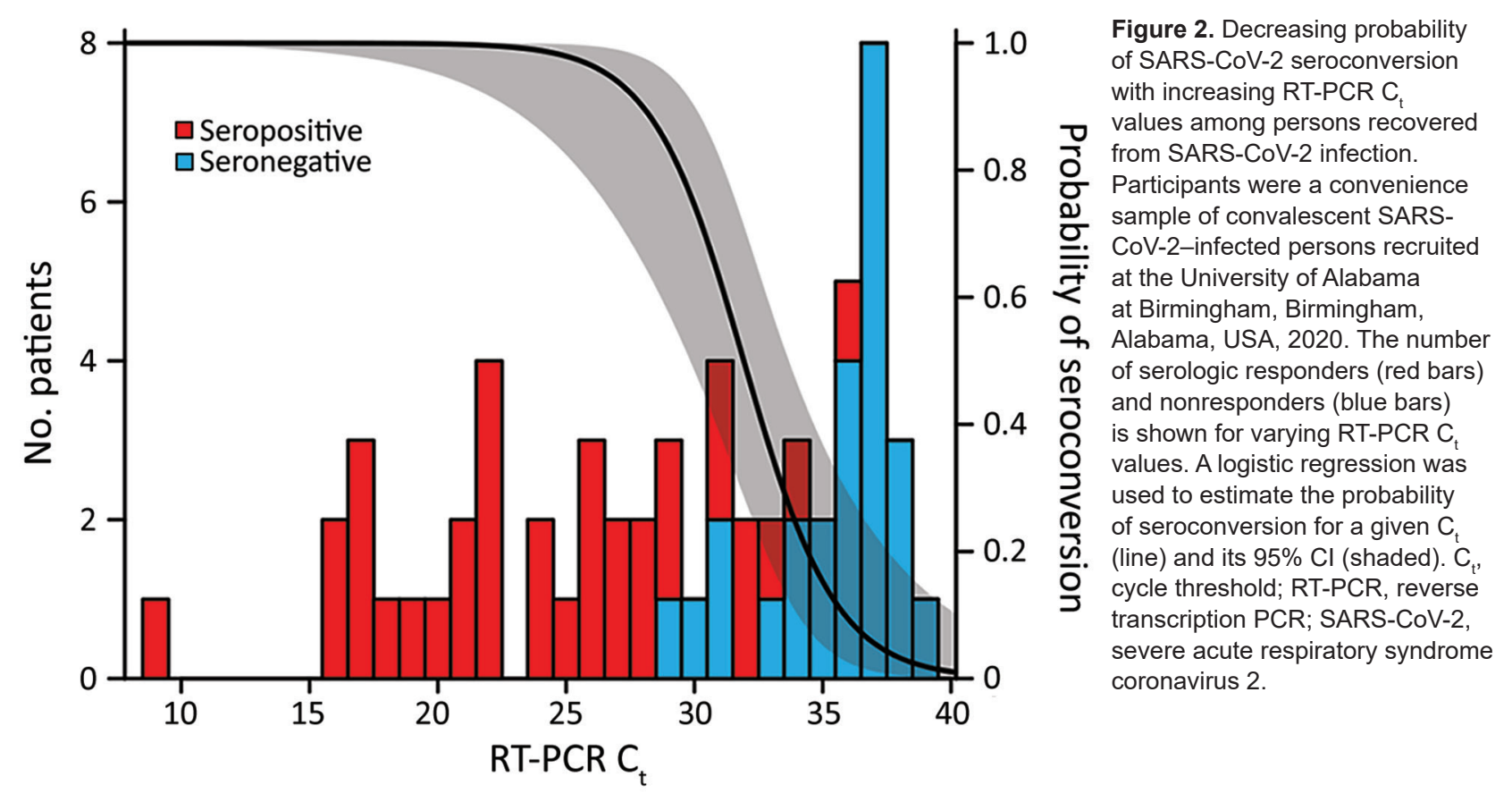

or that they lacked antibodies because they were tested too early. We also examined remnants of purified RNA used for the initial diagnosis for the presence of SARS-CoV-2 sequences. By analyzing 12 available samples (Appendix Table 1), we were able to amplify full-length intact spike genes from 4 specimens, including 2 from seronegative persons with high $C_{t}$ values (Appendix Figure 5).

Finally, we asked whether the relationship between seroconversion, age and $C_{t}$ values was dependent on the diagnostic laboratory. We found that 2 sites with highly sensitive RT-PCR tests (University of Alabama at Birmingham Fungal Reference Laboratory and Children's of Alabama Diagnostic Virology Laboratory in Birmingham) were 6 (95\% CI 2-30) times more likely to identify serologic nonresponders than a third site with a less sensitive test (Assurance Scientific Laboratories in Birmingham) (Appendix Methods). However, this difference did not change the relationship between $C_{t}$ values and seroconversion because seronegative persons had higher $C_{t}$ values than seropositive persons regardless of the test site (Figure 1, panels D, F). In contrast, we observed little association between age and seroconversion at the Assurance Scientific Laboratories site (Figure 1 , panel C), and the difference observed at the other sites was largely driven by young persons who also had high $C_{t}$ values (Figure 1, panel E). Thus, nasopharyngeal viral loads represent a major correlate of the systemic antibody response, whereas age seems to have only a minor effect.

\section{Conclusions}

In summary, we show that patients with low SARS$\mathrm{CoV}-2$ viral loads in their respiratory tract are less likely to mount a systemic antibody response. Although we cannot formally exclude false-positive RTPCR results in some participants, PCR contamination is highly unlikely as an explanation for our findings (Appendix). We also show that clinical illness does not guarantee seroconversion and that laboratories with highly sensitive RT-PCR assays are more likely to detect serologic nonresponders. These results provide an explanation for the puzzling variability of seroconversion in different cohorts.

The fact that a considerable fraction of RT-PCR positive persons fail to seroconvert has practical implications. Such persons remain undetected in seroprevalence studies, including in vaccine studies that assess protection from asymptomatic infection by measuring antibodies to antigens not included in the vaccine. Seroconverters and nonseroconverters will probably also respond differently to vaccination. Recent studies revealed that seropositive persons have a heightened antibody response after the first, but not the second, dose of an mRNA vaccine, suggesting that a single dose is sufficient (11-13; Samanovic et al., unpub. data, https:// doi.org/10.1101/2021.02.07. 21251311). Serologic nonresponders might not exhibit a similarly heightened anamnestic response, but resemble SARS-CoV-2 naive persons, as was observed for 1 previously infected vaccinee who never seroconverted (14). Finally, RT-PCR positive persons who 
experienced COVID-19 symptoms might be less inclined to seek vaccination, believing they are protected, but our results caution against this assumption.

This work was supported by grants from the National Institutes of Health (R01 AI050529, R37 AI150590, P30 AI045008, R01 AI110553, R01 AI36082, P01 AI110657, U19 AI082630). A.N.S. is supported by a training grant (T32 GM07170).

\section{About the Author}

Dr. Liu is a virologist at the University of Pennsylvania. His primary research interests include the evolutionary history and biology of zoonotic pathogens.

\section{References}

1. Kevadiya BD, Machhi J, Herskovitz J, Oleynikov MD, Blomberg WR, Bajwa N, et al. Diagnostics for SARS-CoV-2 infections. Nat Mater. 2021;20:593-605. https:/ / doi.org/10.1038/s41563-020-00906-Z

2. Pinninti SG, Pati S, Poole C, Latting M, Seleme MC, Yarbrough A, et al. Virological characteristics of hospitalized children with SARS-CoV-2 infection. Pediatrics. 2021 Feb 23 [Epub ahead of print]. https:/ / doi.org/10.1542/ peds.2020-037812

3. Sette A, Crotty S. Adaptive immunity to SARS-CoV-2 and COVID-19. Cell. 2021;184:861-80. https:/ / doi.org/10.1016/ j.cell.2021.01.007

4. Gaebler C, Wang Z, Lorenzi JCC, Muecksch F, Finkin S, Tokuyama M, et al. Evolution of antibody immunity to SARS-CoV-2. Nature. 2021;591:639-44. https:/ / doi.org/ 10.1038/ s41586-021-03207-w

5. Fafi-Kremer S, Bruel T, Madec Y, Grant R, Tondeur L, Grzelak L, et al. Serologic responses to SARS-CoV-2 infection among hospital staff with mild disease in eastern France. EBioMedicine. 2020;59:102915. https://doi.org/10.1016/ j.ebiom.2020.102915

6. Oved K, Olmer L, Shemer-Avni Y, Wolf T, Supino-Rosin L, Prajgrod G, et al. Multi-center nationwide comparison of seven serology assays reveals a SARS-CoV-2 non-responding seronegative subpopulation. EClinicalMedicine. 2020; 29:100651. https://doi.org/10.1016/j.eclinm.2020.100651
7. Masia M, Telenti G, Fernandez M, Garcia JA, Agullo V, Padilla S, et al. SARS-CoV-2 seroconversion and viral clearance in patients hospitalized with COVID-19: viral load predicts antibody response. Open Forum Infect Dis. 2021 Jan 5 [Epub ahead of print].

8. Pathela P, Crawley A, Weiss D, Maldin B, Cornell J, Purdin J, et al. Seroprevalence of SARS-CoV-2 following the largest initial epidemic wave in the United States: findings from New York City, May 13-July 21, 2020. J Infect Dis. 2021 Apr 9 [Epub ahead of print]. PMID 33836067

9. Wellinghausen N, Plonné D, Voss M, Ivanova R, Frodl R, Deininger S. SARS-CoV-2-IgG response is different in COVID-19 outpatients and asymptomatic contact persons. J Clin Virol. 2020;130:104542. https://doi.org/10.1016/ j.jcv.2020.104542

10. Thiruvengadam R, Chattopadhyay S, Mehdi F, Desiraju BK, Chaudhuri S, Singh S, et al.; DBT India Consortium for COVID 19 Research. Longitudinal serology of SARS-CoV-2-infected individuals in India: a prospective cohort study. Am J Trop Med Hyg. 2021 May 18 [Epub ahead of print].

11. Krammer F, Srivastava K, Alshammary H, Amoako AA, Awawda MH, Beach KF, et al. Antibody responses in seropositive persons after a single dose of SARS-CoV-2 mRNA vaccine. N Engl J Med. 2021;384:1372-4. https:// doi.org/10.1056/NEJMc2101667

12. Stamatatos L, Czartoski J, Wan YH, Homad LJ, Rubin V, Glantz $\mathrm{H}$, et al. mRNA vaccination boosts cross-variant neutralizing antibodies elicited by SARS-CoV-2 infection. Science. 2021 Mar 25 [Epub ahead of print]. https:/ / doi.org/ 10.1126/science.abg9175

13. Saadat $S$, Rikhtegaran Tehrani Z, Logue J, Newman M, Frieman MB, Harris AD, et al. Binding and neutralization antibody titers after a single vaccine dose in health care workers previously infected with SARS-CoV-2. JAMA. 2021;325:1467-9. https:// doi.org/10.1001/jama.2021.3341

14. Reynolds CJ, Pade C, Gibbons JM, Butler DK, Otter AD, Menacho K, et al.; UK COVIDsortium Immune Correlates Network; UK COVIDsortium Investigators. Prior SARS-CoV-2 infection rescues $B$ and T cell responses to variants after first vaccine dose. Science. 2021 Apr 30 [Epub ahead of print]. https://doi.org/10.1126/science.abh1282

Address for correspondence: Beatrice H. Hahn, Perelman School of Medicine, University of Pennsylvania, 409 Johnson Pavilion, 3610 Hamilton Walk, Philadelphia, PA 19104-6076, USA; email: bhahn@pennmedicine.upenn.edu 